ISSN 2075-471X

www.mdpi.com/journal/laws/

Article

\title{
Decision-Making, Legal Capacity and Neuroscience: Implications for Mental Health Laws
}

\section{Bernadette McSherry}

Melbourne Social Equity Institute, University of Melbourne, 201 Grattan Street, Parkville, Victoria 3010, Australia; E-Mail: bernadette.mcsherry@unimelb.edu.au; Tel.: +61-3-9035-7434

Academic Editor: Kelly Purser

Received: 31 March 2015 / Accepted: 20 April 2015 / Published: 27 April 2015

\begin{abstract}
Neuroscientific endeavours to uncover the causes of severe mental impairments may be viewed as supporting arguments for capacity-based mental health laws that enable compulsory detention and treatment. This article explores the tensions between clinical, human rights and legal concepts of "capacity". It is argued that capacity-based mental health laws, rather than providing a progressive approach to law reform, may simply reinforce presumptions that those with mental impairments completely lack decision-making capacity and thereby should not be afforded legal capacity. A better approach may be to shift the current focus on notions of capacity to socio-economic obligations under the Convention on the Rights of Persons with Disabilities.
\end{abstract}

Keywords: legal capacity; mental capacity; decision-making; mental health laws; neuroscience

\section{Introduction}

Laws that enable the compulsory detention and treatment of individuals with severe mental impairments [1] have been enacted in many countries, including recently in China [2]. While the criteria for compulsory detention and treatment differ across jurisdictions, in general, there must be evidence of "mental illness", generally defined according to certain symptoms, a need for treatment and some form of risk of harm to self or others [3]. Such mental health laws place decision-making about treatment primarily in the hands of clinicians, rather than the individual concerned, thereby enabling what is generally termed "substituted" decision-making.

Some jurisdictions have mental health laws which also require evidence that the person concerned is unable or lacks "capacity" to consent to admission and/or treatment [4]. There have been calls by 
some scholars to focus on "capacity" as the key criterion for compulsory treatment, either through "fused" guardianship and mental health laws [5-7] or, at the very least, via revised mental health laws [8-10] based primarily on a lack of decision-making capacity.

In the clinical realm, there has been an increasing focus on explaining mental impairments in biogenetic terms. The Director of the National Institute of Mental Health in the United States, Thomas Insel, has stated that " $[\mathrm{m}]$ ental disorders are biological disorders involving brain circuits that implicate specific domains of cognition, emotion, or behavior" [11]. He argues that there is a need to move away from diagnostic categories based on symptoms. This neuroscientific approach, as explored below, is not without its critics, but biogenetic explanations for mental impairments may help support the move by certain scholars to argue for mental health laws based primarily on a lack of decision-making capacity. That is, if mental impairments are in fact biological disorders involving brain circuits, the argument can be framed in terms that decision-making may be affected, hence the need for substituted decision-making regimes.

At the international level, however, recent developments in human rights law have challenged not only the scope, but the very existence of mental health laws and substituted decision-making regimes in general [12,13]. Article 12(2) of the United Nations Convention on the Rights of Persons with Disabilities (CRPD), which 159 States have signed and 154 ratified [14], recognises that "persons with disabilities enjoy legal capacity on an equal basis with others in all aspects of life". Such a recognition of universal legal capacity has raised the issue of whether a perceived lack of or impairment of mental capacity, which the United Nations CRPD Committee refers to as "the decision-making skills of a person" ([15], para. 12), should be used as the basis for restrictions in civil law areas relating to compulsory detention and treatment for mental impairments.

This article explores the tensions between clinical, human rights and legal concepts of capacity. I argue that whatever neuroscience may have to offer in terms of enhancing treatment options for those with mental impairments, compulsory detention and treatment should be highly circumscribed and continually challenged on the basis of human rights arguments. Capacity-based mental health laws, rather than providing a progressive approach to law reform, may in fact be buying in to stereotypes and paternalistic assumptions about those with mental impairments. There is a need to ensure that the preferences of those with mental impairments in relation to their treatment and care are heeded and that recent moves towards supported, rather than substituted, decision-making regimes should be given priority. Further, changing the current focus from notions of capacity to socio-economic obligations under the CRPD may assist in highlighting the need for voluntary rather than compulsory treatment.

The first section explores what is meant by legal capacity, how it differs from mental capacity and what this means regarding current debates concerning the scope and existence of mental health laws. The second section then looks at what neuroscience may mean for these debates. The final section explores how a shift away from compulsory detention and treatment towards voluntary treatment might be facilitated. 


\section{Legal Capacity and Decision-Making}

This section explores what is meant by the terms legal and mental capacity and the links between them. I argue that recent interpretations of the CRPD are challenging the way in which individuals with severe mental impairments have been viewed as persons under the law as well as the way in which such persons are treated in the mental health sector.

\subsection{Legal Capacity and the Convention on the Rights of Persons with Disabilities}

The Council of Europe's Commissioner for Human Rights defines "legal capacity" ([16], p. 7) as "a person's power or possibility to act within the framework of the legal system". I have argued previously that there are two constituent elements to legal capacity [17]. The first refers to "legal standing" in the sense of being viewed as a person before the law; the second to "legal agency" or what is sometimes referred to as "active legal capacity".

At various times in different societies, certain groups have been viewed as not having legal personhood or standing. The extinction or suspension of legal standing, sometimes referred to as "civil death", was once seen as a necessary consequence of conviction. Similarly, women, children under the age of majority and persons with mental and/or intellectual impairments have been and continue to be viewed in some societies as not having legal standing. I will return later to the example of how women's legal standing and agency have been viewed.

Legal agency refers to the ability to act within the framework of the legal system. Article 12(3) of the CRPD states that "States Parties shall take appropriate measures to provide access by persons with disabilities to the support they may require in exercising their legal capacity" [14]. The reference to exercising legal capacity ensures that legal agency is also encompassed by the concept of legal capacity within the CRPD. It is this aspect of legal capacity that has been the focus of recent writing in relation to those with mental and intellectual impairments.

Gerard Quinn and Anna Arstein-Kerslake ([18], p. 42) have conceptualised the exercise of legal capacity in terms of it being both a sword and a shield. Used as a sword, the exercise of legal capacity reflects an individual's right to make decisions for him or herself and to have those decisions respected by others. Such decisions include the right to marry and to have a family, the right to enter into contracts such as to buy a house or to be employed, the right to make a will and so on. Used as a shield, the exercise of legal capacity refers to the power of the individual to stop others from purporting to make decisions on his or her behalf.

Article 12 thus makes it clear that those with disabilities have legal capacity on an equal basis with others. This must be presumed. The question then is: can legal capacity ever be removed and, if so, in which circumstances? Can a person's purported lack of "mental" capacity be sufficient? The next two sections explore what is meant by mental capacity and the link it has traditionally had with how individuals with mental impairments are treated within the framework of the legal system.

\subsection{Mental Capacity and Decision-Making}

As previously pointed out, the United Nations CRPD Committee ([15], para. 12) defines "mental capacity" as "the decision-making skills of a person". Gareth Owen and colleagues ([19], p. 81) have 
noted that the "conceptual literature on mental capacity is complex because it mixes philosophical, legal and psychiatric vocabularies".

Traditionally, an assessment of decision-making skills has focused on a person's cognitive abilities. For example, the Mental Capacity Act 2005 (England and Wales) takes a cognitive approach to displacing legal capacity and enabling substituted decision-making. Section 2(1) of that Act states that "a person lacks capacity in relation to a matter if at the material time he [or she] is unable to make a decision for himself [or herself] in relation to the matter because of an impairment of, or a disturbance in the functioning of, the mind or brain". Section 3(1) then sets out that a person is unable to make a decision if that person is unable-

(a) To understand the information relevant to the decision,

(b) To retain that information,

(c) To use or weigh that information as part of the process of making the decision, or

(d) To communicate his decision (whether by talking, using sign language or any other means).

This test is sometimes referred to as a "functional" test in that it assesses decision-making abilities on an issue-specific basis, recognising that mental capacity may fluctuate and that it needs to be assessed at a particular time in relation to a particular decision. The functional test has influenced mental health law reform endeavours in Tasmania and Western Australia [20]. The Mental Health Act 2013 (Tas), for example, now includes a "decision-making capacity" criterion for assessment and compulsory treatment. Section 7(1) of that Act states:

For the purposes of this Act, an adult is taken to have the capacity to make a decision about his or her own assessment or treatment (decision-making capacity) unless it is established, on the balance of probabilities, that:

(a) he or she is unable to make the decision because of an impairment of, or disturbance in, the functioning of the mind or brain; and

(b) he or she is unable to:

(i) understand information relevant to the decision; or

(ii) retain information relevant to the decision; or

(iii) use or weigh information relevant to the decision; or

(iv) communicate the decision (whether by speech, gesture or other means).

The phrase "an impairment of, or disturbance in, the functioning of the...brain" appears to reflect neuroscientific endeavours to find the causes of mental impairments as located within the brain and neural circuits. I will return to this point a little later.

\subsection{The Link between Legal and Mental Capacity}

Genevra Richardson ([21], p. 89) writes in relation to the concept of mental capacity:

For the law, mental capacity is an essential ingredient of individual autonomy and is employed to define the line between legally effective and legally ineffective decisions. Those with mental capacity will have the legal capacity to act: their decisions or choices will be respected. In contrast, those who lack mental capacity will also lack legal capacity: 
their decisions and choices will not be respected and decisions will be made by others on their behalf.

Mental or decision-making capacity is therefore at present closely linked to legal capacity in certain jurisdictions. Interpretations of the CRPD are, however, challenging this link.

In 2014, the United Nations Committee on the CRPD in its General Comment on Article 12 stated ([15], para. 13) that "[u]nder article 12 of the Convention, perceived or actual deficits in mental capacity must not be used as justification for denying legal capacity". It pointed out that:

the concepts of mental and legal capacity have been conflated so that where an individual is thought to have impaired decision-making skills, often because of a cognitive or psychosocial disability, her legal capacity to make a particular decision is removed... Article 12 does not permit this discriminatory denial of legal capacity...([15], para. 13).

Laws that enable compulsory treatment on the basis of a loss of decision-making capacity on this view are discriminatory. Mental or decision-making capacity should no longer be intrinsically linked to legal capacity and reforms that have headed in this direction should be halted. In Genevra Richardson's words ([21], p. 92), "in its purest form there is no point beyond which legal capacity is lost. There is no binary divide".

From a clinical viewpoint, the Committee's "purist" approach may prove difficult to accept, particularly in the light of the developing emphasis on biogenetic explanations of mental impairments. The next section turns to an overview of how neuroscience views decision-making by those experiencing mental impairments and how this can be seen as supporting calls for mental health laws based on the traditional link between legal and mental capacity.

\section{Neuroscience and the Organic Disease Model of Mental Impairments}

Neuroscience is a broad term used to describe the study of the brain and the nervous system and "decision neuroscience" is a relatively new field which seeks to explore the neural basis for decision-making. Peter Zachar and Kenneth S. Kendler refer to "psychiatric disorders" as being viewed by some researchers and clinicians as:

due to pathological processes in specific parts or systems of the brain. Both the historical and current advocates of this model stress the affinity of psychiatry to neurology and typically view psychiatry as "applied brain science" ([22], p. 560).

The desire to view mental impairments as stemming from pathological brain functioning is understandable, given that attempts to find a "natural" basis for mental impairments goes back to at least the 4th century B.C. with Hippocrates suggesting that mental health could be affected by the four humours, namely blood, phlegm, yellow and black bile ([23], pp. 33-36).

As well as looking for the cause of mental impairments in brain functioning, other "organic disease" lines of enquiry examine biological and genetic components in order to pinpoint their cause(s). Sven Speerforck, Georg Schomerus, Susanne Pruess and Matthias C. Angermeyer explain that: 
'biogenetic explanations' is a broadly defined term which encompasses different causal explanations like 'chemical imbalance of the brain', 'brain disease' or 'heredity'... ([24], p. 224).

At present, the two main psychiatric manuals, the Diagnostic and Statistical Manual of Mental Disorders [25] and the International Classification of Diseases and Health Related Problems [26] take the approach of describing symptoms in observational terms and then classifying them into syndromes. Derek Bolton writes that this is generally done by using "an algorithm leading from symptoms to syndromes, such that either this or that symptom is necessary for diagnosis, or that some number, say five out of a possible ten are sufficient" ([27], p. 4). Ian Hickie and colleagues write that "[i]t is frustrating that diagnoses are largely based on descriptive phenomena. Often they vary from practitioner to practitioner, and may well change markedly over the course of illness..." ([28], p. 2).

Criticisms of these classification systems have contributed to the search for biogenetic explanations for mental disorders. Perhaps unsurprisingly, there is a dispute occurring in psychiatric circles concerning whether psychiatry should be viewed as a "clinical neuroscience" because mental disorders are "brain diseases" or whether it should adopt a "psychosocial model" where mental disorders are conceptualised as understandable responses to environmental factors or problematic interpersonal relationships [29].

Leaving that dispute to one side, from a clinical perspective, mental impairments are often viewed as causing a lack of "insight" into a particular diagnosis. While insight is a rather vague term, it is generally taken to refer to a person's self-awareness that there is a problem or an illness and an understanding of its cause or meaning ([30], p. 528). A lack of insight or poor insight has been associated with the most severe mental impairments such as schizophrenia and bipolar disorder and while theories of the cause of this have ranged from "denial" to a preference for psychosis, there is a growing literature suggesting that damage to frontal lobe areas may lead to an unawareness of the illness. This is sometimes referred to as anosognosia [31,32].

From a clinical perspective, it could be argued that if a person is unaware of or only partially aware that he or she has an illness, it is in that person's best interests to go ahead with treatment with the aim of improving insight. On this basis the ends could be said to justify the means in relation to compulsory treatment.

The concept of insight has also been identified as playing an important role in mental health tribunal hearings [33-35]. That is, people brought within the civil commitment system are often presumed to have no insight into their illness on the basis that any "rational" person would voluntarily consent to hospital admission and mental health treatment. The refusal of mental health treatment may in itself be regarded as indicative of the perception that the person concerned is unable to make a valid decision.

If mental impairments are seen as stemming from dysfunctional brain processes which affect reasoning, it would seem that laws enabling substituted decision-making are justifiable. This view provides impetus for capacity-based mental health laws. In 2006, John Dawson and George Szmukler proposed a "fused" model of mental health and guardianship law based on an individual's incapacity to make treatment decisions [5]. They argued that mental incapacity and best interests should be the basis for compulsory treatment. Together with Rowena Daw, they subsequently developed a draft model statute which was published in a special volume of the Journal of Mental Health together with a series of commentaries [6]. In defending the fusion proposal, Rowena Daw wrote that "[a]ssessing 
capacity is already an essential component of medical and social care practice. An assessment of capacity is not necessarily less reliable than the current tests for a compulsory order" ([7], p. 111).

Other authors have argued that compulsory treatment based on mental (in)capacity is preferable to treatment based on risk of self-harm or harm to others [8-10]. This argument emphasises that risk assessment is not an exact science and very difficult to carry out when the base rate of those with mental impairments is low ([36], chapters 3 and 5).

There is a certain attraction to the idea that mental impairments are caused by dysfunctional brain processing which in turn causes a lack of insight that justifies substituted decision-making. This, however, over-estimates the state of knowledge in this regard. The next section expands upon this point and outlines some of the negative consequences of taking a reductionist approach towards mental impairments and decision-making skills.

\section{Criticisms of Neuroscience and the Mental Capacity Approach}

There is a growing literature which falls under the banner "critical neuroscience" that argues that the findings from neuroimaging data are under-theorised and over-hyped [37,38]. Sabrina Ali, Michaeld Lifshitz and Amir Raz, for example, have coined the term "neuroenchantment" to describe the "sub-judicious fascination with brain science" ([39], p. 1). They argue that critical judgment can be clouded by "the allure of neuroscience" ([39], p. 1).

It is important not to over-estimate the present state of knowledge concerning mental impairments. Derek Bolton has pointed out that the very notion of "mental disorder" is a contested one [27] and even if a definition can be agreed upon, there may be multiple causes of psychopathology. As Allen J. Frances and Thomas Widiger point out, neuroscience may be providing information about how the "normal" brain works, but understanding how things can go wrong in brain function will take decades [40].

There is also a danger in believing that neuroscience can positively influence how those with mental impairments are perceived and treated in a social context. Article 12(1) makes it clear "that persons with disabilities have the right to recognition everywhere as persons before the law". This counteracts historical practices where certain groups have been discriminated against on the basis of "science" and legal capacity not granted to them.

For example, women have traditionally been, and in some countries are still seen as, lacking the requisite abilities to make decisions. In 1912, Viscount Helmsley, in opposing the enfranchisement of women said:

[T] he mental equilibrium of the female sex is not as stable as the mental equilibrium of the male sex. The argument has very strong scientific backing... [41].

Currently, in popular culture, the differences between men and women's brains are seen as reinforcing gender stereotypes. Simon Baron-Cohen for example has stated that: "[p]eople with the female brain make the most wonderful counsellors, primary-school teachers, nurses, carers, therapists, social workers, mediators, group facilitators or personnel-staff" ([42], p. 185). Neil Levy has criticised the approach taken by Baron-Cohen [43] and various authors have coined the term neurosexism to explain how some have used neuroscience to reinforce gender stereotypes [44-46]. 
In a similar way, those considered "insane" have long been presumed to lack the requisite abilities to make decisions. Henry de Bracton wrote in 1256 :

A lunatic cannot stipulate or conduct any transaction because he does not understand what he is doing ([47], p. 286)...[lunatics] are not far removed from brutes ([47], p. 424).

Michael Perlin has coined the term "sanism" to describe "an irrational prejudice of the same quality and character of other irrational prejudices that cause (and are reflected in) prevailing social attitudes of racism, sexism, homophobia, and ethnic bigotry" ([48], p. 34). Stressing biogenetic causes for mental impairments may simply reinforce sanism in the form of discrimination and presumptions about a lack of insight or decision-making capacity.

There is some indication that this is already occurring. Sven Speerforck and colleagues have found that causal beliefs such as "chemical imbalance of the brain" and "brain disease" were related to "a stronger desire for social distance towards persons with major depression or schizophrenia" and that they were positively correlated with stigmatising attitudes [24].

Similarly, Erlend P. Kvaale, Nick Haslam and William H. Gottdiener have found that biogenetic explanations for mental impairments may serve to reduce blame, but "induce prognostic pessimism and negative stereotyping regarding dangerousness" [49].

The recent pronouncement quoted above by the United Nations Committee on the CRPD that "perceived or actual deficits in mental capacity must not be used as justification for denying legal capacity" ([15], para. 13) challenges moves towards capacity-based mental health laws. Such a pronouncement can be viewed as trying to counteract the presumption that certain mental impairments necessitate substituted decision-making.

Nevertheless, authors such as Sascha Callaghan and Christopher Ryan insist that it "remains useful to conceptualise legal capacity with regard to a person's ability to make a decision" ([50], p. 756). This is a narrow approach to the concept of (in)equality before the law. As pointed out above, in many societies, prisoners for example, are viewed as not having legal capacity which suggests that something more is going on than just measuring decision-making ability in relation to which groups are viewed as being equal before the law.

What then is envisaged if mental capacity is de-linked from legal capacity? Will this mean that individuals with severe mental impairments who might benefit from psychiatric treatment should be left, in Darold Treffert's ([51], p. 1041) oft-quoted phrase, “dying with their rights on"?

Kristen Booth Glen ([52], pp. 98-99) has observed:

[The CRPD] sees incapacity as socially constructed, insists on the full legal capacity of every person with [disabilities], and does away with substituted decision-making in favor of society's obligation to provide appropriate supports to permit everyone to make his or her own decisions. Like every emerging paradigm, this challenges our perceptions and our understanding of when, how, and even if the state may intervene in a person's life, and it has the potential to be deeply unsettling. And, unsurprisingly, it takes time... This new conceptualization based on international human rights may initially appear hopelessly utopian, or dangerously naive. Why? Because it is a new way of thinking, a radically different view, a reorientation rather than an incremental change. [Emphasis in original]. 
The next section explores how obligations on States to provide supports and services for persons with disabilities under the CRPD might provide a more nuanced approach to mental health care and treatment than focusing on substituted decision-making regimes.

\section{Moving Beyond Capacity Debates}

Terry Carney in this journal has explored the ways in which law reform bodies are taking up the challenge to find ways of supporting decision-making rather than staying with the status quo of substituted decision-making for those with "cognitive impairments" [53]. He addresses recent law reform proposals including those of the Australian Law Reform Commission in relation to "supporters" and "representatives" of those with mental and intellectual impairments [54]. Carney argues that there is a case for "hastening slowly" in this regard in order to ensure a proper evidence base for "genuine" supported decision-making ([53], p. 53).

Endeavours to provide both informal and more formal supports for those with mental and intellectual impairments to make their own decisions should be welcomed. However, in the mental health field, the major drawback to the current law reform focus on Article 12 and matters of capacity is that it serves to keep attention on compulsory detention and treatment, rather than viewing the CRPD as an opportunity to find new ways of ensuring voluntary access to the highest attainable standard of mental health services and community care.

The CRPD as a whole combines civil and political rights, which are often referred to as "negative" rights in the sense of freedom from state interference, with economic, social, and cultural rights, which are often referred to as "positive" rights in placing obligations on States Parties to ensure certain rights are upheld. Peter Bartlett points out that the CRPD has changed the traditional relationship between civil and political and socio-economic rights, so that the division between the two is more "nebulous" than ever before, thereby reinforcing the indivisibility and interdependent character of rights ([55], p. 757).

Article 25 of the CRPD refers to the right to the enjoyment of the highest attainable standard of health without discrimination on the basis of disability. It sets out a number of "positive" socio-economic obligations on States to provide, amongst other matters, necessary health services and to ensure health professionals provide care on the basis of free and informed consent (Article 25(b) and (d)). Article 19 of the CRPD refers to the right to live in the community, with choices equal to others and also sets out a number of obligations including the provision of "personal assistance necessary to support living and inclusion in the community, and to prevent isolation or segregation from the community" (Article 19(b)). Emphasising the importance of these obligations may go some way towards focusing endeavours on support in general, thereby increasing voluntary access to services rather than the current emphasis on compulsory treatment and care [20].

Such socio-economic obligations reflect and support broader movements in health services towards "patient-centered" care. The Institute of Medicine in the United States defines patient-centered care as "providing care that is respectful of and responsive to individual patient preferences, needs, and values and ensuring that patient values guide all clinical decisions" ([56], p. 6). Mental health policy throughout the developed world has been influenced by this move towards individualised treatment and care and is increasingly influenced by the tenets of the "Recovery approach" [57,58]. This approach does not comprise a tightly prescriptive set of rules with respect to mental health care but 
rather is "a set of ideas and principles derived from the experiences of people with mental health problems" ([59], p. 6). Larry Davidson and colleagues note ([60], p. 484) that "people must assume primary responsibility for their transformation from a disabled person to a person in recovery...People must also be afforded opportunities to succeed and fail' ' [italics added].

The Recovery approach, supported by an increasing emphasis on individualised care and human rights, emphasises choice and autonomy rather than assuming the necessity of substituted decision-making. Importantly, what is claimed is not simply empowerment to be able to make choices around simple and uncontentious matters, but also the autonomy to make "risky and potentially self-defeating choices" ([61], p. 28).

Ultimately, as Peter Bartlett ([62], p. 834) has observed:

If appropriate services and supports are provided, the argument goes, compulsion will be no more necessary for people with mental disabilities than for anyone else. There is much to recommend this view in many circumstances, including those related to psychiatric and related detention. Thus, in much of Europe, provision of proper community housing and community support would provide an option likely to be preferred by many people with mental disabilities. If services are provided that people want, it will not be necessary to force them to use them. For a large number of people in psychiatric and related institutions this is almost certainly a convincing argument. And, if the state refuses to offer services that people do want to use, it is ethically dubious to force them to use services they do not want to use.

A focus on socio-economic obligations may ultimately be more important in implementing the CRPD through respecting the will and preferences of individuals with mental impairments and lifting their status and participation in society, than concentrating solely on their decision-making skills and presumed lack of insight.

\section{Conclusions}

The study of the neurological and genetic roots of severe mental impairments may lead to better treatments, but in terms of the law, it is apposite to follow Stephen Morse's approach that "neuroscience has many things to say, but not nearly as much as people would hope" ([63], p. 243).

Mario Maj has pointed out that the best way forward for psychiatry is to rest on the basis of "social neuroscience" [29]. He views this as one way of developing interdisciplinary research that avoids the either/or dichotomy of the brain being studied as a biological machine in isolation from psychosocial factors. This seems to be appropriate given that a simplistic, reductionist account of the causes of mental impairments brings with it the dangers of sanism and discrimination. Those who experience mental impairments are individuals first and foremost; mental impairments should not be viewed as defining them.

While debates about the need for and scope of mental health laws will undoubtedly continue, compliance with the CRPD, as Terry Carney and Fleur Beaupert note [64], goes well beyond law reform, to reforms in service provision and social attitudes. Ultimately, it is through emphasising the socio-economic obligations placed on States Parties and, in particular, the obligation to provide services adapted to individual needs that genuine reforms in mental health care and treatment can occur. 


\section{Conflicts of Interest}

The author declares no conflict of interest.

\section{References and Notes}

1. I will use the term mental impairments throughout this Article because this is the term used in Article 1 of the Convention on the Rights of Persons with Disabilities. I acknowledge that this term will not placate some readers and, that, as expressed by Don Coyhis, "words are important. If you want to care for something, you call it a 'flower'; if you want to kill something, you call it a 'weed"': Don Coyhis, member of the Mohican Nation from the Stockbridge-Munsee Reservation in Wisconsin in William White. "The Rhetoric of Recovery Advocacy: An Essay on the Power of Language." In Let's Go Make Some History: Chronicles of the New Addition Recovery Movement. Washington: Johnson Institute and Faces and Voices of Recovery, 2006, pp. 37-76. Available online: http://naabt.org/documents/LANGUAGEBillWhite.pdf (accessed on 27 April 2015).

2. Hanhui Chen, Michael R. Phillips, Hui Cheng, Qiongqiong Chen, Xiaodong Chen, Drew Fralick, Yine'e Zhang, Meng Liu, Jia Huang, and Marlys Bueber. "Mental Health Law of the People's Republic of China (Translated and annotated version of China's new Mental Health Law)." Shanghai Archives of Psychiatry 24 (2012): 305-21.

3. John Ellery Gray, Bernadette McSherry, Richard L O'Reilly, and Penelope Weller. "Australian and Canadian Mental Health Acts Compared." Australian and New Zealand Journal of Psychiatry 44 (2010): 1126-31.

4. See, for example, Mental Health and Related Services Act (NT) s 14; Mental Health Act 2013 (Tas) s 40; Mental Health Act 2014 (WA) s 25.

5. John Dawson, and George Szmukler. "The Fusion of Mental Health and Incapacity Legislation." British Journal of Psychiatry 188 (2006): 504-09.

6. George Szmukler, Rowena Daw, and John Dawson. “A Model Law Fusing Incapacity and Mental Health Legislation." Journal of Mental Health Law 11 (2010): 11-25.

7. Rowena Daw. "The Case for a Fusion Law: Challenges and Issues." In Coercive Care. Edited by Bernadette McSherry and Ian Freckelton. Abingdon: Routledge, 2013, pp. 93-113.

8. Matthew Large, Christopher Ryan, Olav Nielssen, and Robert Hayes. "The Danger of Dangerousness: Why We Must Remove the Dangerousness Criterion from Our Mental Health Acts." Journal of Medical Ethics 34 (2008): 877-81.

9. Christopher Ryan. "Capacity as a Determinant of Non-Consensual Treatment of the Mentally Ill in Australia." Psychiatry, Psychology and Law 18 (2011): 248-62.

10. Christopher Ryan, Olav Nielssen, Michael Paton, and Matthew Large. "Clinical Decisions in Psychiatry Should Not Be Based on Risk Assessment." Australasian Psychiatry 18 (2010): 398-403.

11. Thomas Insel. "Transforming Diagnosis." NIMH Director's Blog, 29 April 2013. Available online: http://www.nimh.nih.gov/about/director/2013/transforming-diagnosis.shtml (accessed on 27 April 2015).

12. See, for example, Bernadette McSherry, and Penelope Weller, eds. Rethinking Rights-Based Mental Health Laws. Oxford: Hart Publishing, 2010.

13. Bernadette McSherry. "Mental Health Laws: Where to From Here?" Monash University Law Review 40 (2014): 175-97. 
14. Secretariat for the Convention on the Rights of Persons with Disabilities. "Rights and Dignities of Persons with Disabilities (adopted 13 December 2006, GA Res 61/106)." UN Enable, 2015. Available online: http://www.un.org/disabilities/ (accessed on 27 April 2015).

15. United Nations Committee on the Rights of Persons with Disabilities. "General Comment No. 1 (2014), Article 12: Equal Recognition before the Law (U.N. Doc. CRPD/C/GC/1).” Available online: http://daccess-dds-ny.un.org/doc/UNDOC/GEN/G14/031/20/PDF/G1403120.pdf?OpenElement (accessed on 27 April 2014).

16. Council of Europe Commissioner for Human Rights. The Right of People with Disabilities to Live Independently and Be Included in the Community. France: Council of Europe Publishing, 2012. Available online: https://wcd.coe.int/ViewDoc.jsp?id=1917847 (accessed on 27 April 2015).

17. Bernadette McSherry. "Legal Capacity under the Convention on the Rights of Persons with Disabilities." Journal of Law and Medicine 20 (2012): 22-27.

18. Gerard Quinn, and Anna Arstein-Kerslake. "Restoring the 'Human' in 'Human Rights': Personhood and Doctrinal Innovation in the UN Disability Convention." In The Cambridge Companion to Human Rights Law. Edited by Conor Gearty and Costas Douzinas. Cambridge: Cambridge University Press, 2012, pp. 36-55.

19. Gareth Owen, Fabian Freyenhagen, Genevra Richardson, and Matthew Hotopf. "Mental Capacity and Decisional Autonomy: An Interdisciplinary Challenge.” Inquiry 52 (2009): 79-107.

20. Bernadette McSherry, and Kay Wilson. "The Concept of Capacity in Australian Mental Health Law Reform: Going in the Wrong Direction?" International Journal of Law and Psychiatry, 2015, forthcoming.

21. Genevra Richardson. "Mental Capacity in the Shadow of Suicide: What Can the Law Do?" International Journal of Law in Context 9 (2013): 87-105.

22. Peter Zachar, and Kenneth S. Kendler. "Psychiatric Disorders: A Conceptual Taxonomy." American Journal of Psychiatry 164 (2007): 557-65.

23. Franz G. Alexander, and Sheldon T. Selesnick. The History of Psychiatry: An Evaluation of Psychiatric Thought and Practice from Prehistoric Times to the Present. New York: Harper and Row, 1966.

24. Sven Speerforck, Georg Schomerus, Susanne Pruess, and Matthias C. Angermeyer. "Different Biogenetic Causal Explanations and Attitudes towards Persons with Major Depression, Schizophrenia and Alcohol Dependence: Is the Concept of a Chemical Imbalance Beneficial?" Journal of Affective Disorders 168 (2014): 224-28.

25. American Psychiatric Association. Diagnostic and Statistical Manual of Mental Disorders (DSM-5), 5th ed. Washington: American Psychiatric Publishing Inc., 2013.

26. World Health Organization. The ICD-10 Classification of Mental and Behavioural Disorders: Clinical Descriptions and Diagnostic Guidelines. Geneva: World Health Organization, 1992.

27. Derek Bolton. What is Mental Disorder? An Essay in Philosophy, Science and Values. Oxford: Oxford University Press, 2008.

28. Ian B. Hickie, Jan Scott, Daniel F. Hermens, Elizabeth M. Scott, Sharon L. Naismith, Adam J. Guastella, Nick Glozier, and Patrick D. McGorry. "Clinical Classification in Mental Health at the Cross-Roads: Which Direction Next?” BMC Medicine 11 (2013): 125. 
29. Mario Maj. "Social Neuroscience as an Ideal Basic Science for Psychiatry." World Psychiatry 13 (2014): 105-06.

30. Gordon D. Strauss. "Diagnosis and Psychiatry: Examination of the Psychiatric Patient." In Comprehensive Textbook of Psychiatry, 6th ed. Edited by Harold I. Kaplan and Benjamin J. Sadock. Baltimore: Williams and Wilkins, 1995, vol. 1.

31. Lorenzo Pia, and Marco Tamietto. "Unawareness in Schizophrenia: Neuropsychological and Neuroanatomical Findings." Psychiatry and Clinical Neurosciences 60 (2006): 531-37.

32. Mujeeb U. Shad, Carol A. Tamminga, Munro Cullum, Gretchen L. Haas, and Matcheri S. Keshavan. "Insight and Frontal Cortical Function in Schizophrenia: A Review." Schizophrenia Research 86 (2006): 54-70.

33. Kate Diesfeld. "Insight: Unpacking the Concept in Mental Health Law." Psychiatry, Psychology and Law 10 (2003): 63-70.

34. Kate Diesfeld, and Stefan Sjöström. "Interpretive Flexibility: Why Doesn't Insight Incite Controversy in Mental Health Law." Behavioral Sciences and the Law 25 (2007): 85-101.

35. Ian Freckelton. "Extra-Legislative Factors in Involuntary Status Decision-Making." In Rethinking Rights-Based Mental Health Laws. Edited by Bernadette McSherry and Penelope Weller. Oxford: Hart Publishing, 2010, pp. 203-30.

36. Bernadette McSherry. Managing Fear: The Law and Ethics of Preventive Detention and Risk Assessment. New York: Routledge, 2014.

37. Des Fitzgerald, Svenja Matusall, Joshua Skewes, and Andreas Roepstorf. "What's So Critical about Critical Neuroscience?-Rethinking Experiment, Enacting Critique." Frontiers in Human Neuroscience 8 (2014): 365. doi:10.3389/fnhum.2014.00365.

38. Stephan Schleim. "Critical neuroscience-Or critical science? A perspective on the perceived normative significance of neuroscience." Frontiers in Human Neuroscience 8 (2014): 336. doi:10.3389/fnhum.2014.00336.

39. Sabrina S. Ali, Michael Lifshitz, and Amir Raz. "Empirical Neuroenchantment: From Reading Minds to Thinking Critically." Frontiers in Human Neuroscience 8 (2014): 357. doi:10.3389/ fnhum.2014.00357.

40. Allen J. Frances, and Thomas Widiger. "Psychiatric Diagnosis: Lessons from the DSM-IV Past and Cautions for the DSM-5 Future." Annual Review of Psychology 8 (2012): 109-30.

41. United Kingdom. "Parliamentary Debates (Hansard), House of Commons, 28 March 1912, 642 (Viscount Helmsley)." Available online: http://hansard.millbanksystems.com/commons/1912/ mar/28/parliamentary-franchise-women-bill (accessed on 27 April 2015).

42. Simon Baron-Cohen. Essential Difference: Male and Female Brains and the Truth about Autism. New York: Basic Books, 2004.

43. Neil Levy. "Book review: Understanding Blindness." Phenomenology and the Cognitive Sciences 3 (2004): 315-24.

44. Cordelia Fine. Delusions of Gender: The Real Science behind Sex Differences. London: Icon, 2010.

45. Robyn Bluhm. "Beyond Neurosexism: Is It Possible to Defend the Female Brain?" In Neurofeminism: Issues at the Intersection of Feminist Theory and Cognitive Science. Edited by Robyn Bluhm, Anne Jaap Jacobson and Heidi Lene Maibom. New York: Palgrave Macmillan, 2012.

46. Isabelle Dussauge, and Anelis Kaiser. "Neuroscience and Sex/Gender." Neuroethics 5 (2012): 211-15. 
47. Henry De Bracton. Bracton De Legibus et Consuetudinibus Angliae (Bracton on the Laws and Customs of England). Edited by George E. Woodbine. Translated with revisions and notes by Samuel E. Thorne. Buffalo and New York: William S. Hein \& Co, 1997 (c. 1256).

48. Michael L. Perlin. International Human Rights and Mental Disability Law: When the Silences are Heard. New York: Oxford University Press, 2012.

49. Erlend P. Kvaale, Nick Haslam, and William H. Gottdiener. "The 'Side-Effects' of Medicalization: A Meta-Analytic Review of How Biogenetic Explanations Affect Stigma." Clinical Psychology Review 33 (2013): 782-94.

50. Sascha Mira Callaghan, and Christopher Ryan. "Is There a Future for Involuntary Treatment in Rights Based Mental Health Law?" Psychiatry, Psychology and Law 21 (2014): 747-66.

51. Darold A. Treffert. "Letters: Dying with Their Rights on." American Journal of Psychiatry 130 (1973): 1041. doi:abs/10.1176/ajp.130.9.1041.

52. Kristin Booth Glen. "Changing Paradigms: Mental Capacity, Legal Capacity, Guardianship, and Beyond.” Columbia Human Rights Law Review 44 (2012): 93-169.

53. Terry Carney. "Supported Decision-Making for People with Cognitive Impairments: An Australian Perspective." Laws 4 (2015): 37-59.

54. Australian Law Reform Commission. Equality, Capacity and Disability in Commonwealth Laws: Final Report. Sydney: ALRC, 2014.

55. Peter Bartlett. "The United Nations Convention on the Rights of Persons with Disabilities and Mental Health Law." The Modern Law Review 75 (2012): 752-78.

56. Institute of Medicine. Crossing the Quality Chasm: A New Health System for the Twenty-First Century. Washington: National Academy Press, 2001.

57. State of Victoria, Department of Health. Framework for Recovery-Oriented Practice. Melbourne: Mental Health, Drugs and Regions Division, 2011.

58. David Skuse. "Recovery." International Psychiatry 9 (2012): 3. Available online: https://www.rcpsych.ac.uk/pdf/IPv9n1.pdf (accessed on 27 April 2015).

59. Jed Boardman, and Geoff Shepher. "Implementing Recovery in Mental Health Services." International Psychiatry 9 (2012): 6-8.

60. Larry Davidson, Maria J. O’Connell, Janis Tondora, Martha Lawless, and Arthur C. Evans. "Recovery in Serious Mental Illness: A New Wine or Just a New Bottle?" Professional Psychology: Research and Practice 36 (2005): 480-87.

61. Craig Parsons. "The Dignity of Risk: Challenges in Moving On." Australian Nursing Journal 15 (2008): 28.

62. Peter Bartlett. "A mental disorder of a kind or degree warranting confinement: Examining justifications for psychiatric detention." International Journal of Human Rights 16 (2012): 831-44.

63. Stephen J. Morse. "Criminal Law and Neuroscience: Present and Future." Northern Ireland Legal Quarterly 65 (2014): 243-58.

64. Terry Carney, and Fleur Beaupert. "Public and Private Bricolage-Challenges Balancing Law, Services and Civil Society in Advancing CRPD Supported Decision-Making." The University of New South Wales Law Journal 36 (2013): 175-201.

(C) 2015 by the author; licensee MDPI, Basel, Switzerland. This article is an open access article distributed under the terms and conditions of the Creative Commons Attribution license (http://creativecommons.org/licenses/by/4.0/). 